\title{
A PAISAGEM PARANAENSE SOB O OLHAR DE ARMIN HENKEL $^{1}$
}

\author{
Luis Afonso Salturi ${ }^{2}$
}

- Enviado em 17/08/2015

- Aprovado em 10/09/2015

\begin{abstract}
RESUMO
O presente artigo trata sobre a obra do fotógrafo alemão Armin Henkel (1882-1962) que se radicou em Curitiba. São analisadas fotografias que registram vários locais do Paraná, produzidas entre o final da década de 1930 e meados da década de 1950. Esse material é analisado a partir dos pressupostos teóricos e metodológicos da Sociologia. Trata-se do primeiro trabalho sobre esse fotógrafo que possuía um estúdio fotográfico em Curitiba e cujas informações biográficas são escassas. A obra de Armin Henkel tem grande importância sociológica e histórica, na medida em que suas fotografias registraram momentos da cultura e da paisagem brasileira, produções que posteriormente se transformavam em cartões postais.
\end{abstract}

Palavras-chave: Armin Henkel. Fotografia no Paraná. Paisagem paranaense.

\section{A FOTOGRAFIA NO PARANÁ E OS REGISTROS DA PAISAGEM}

No Brasil, os primeiros registros fotográficos se deram a partir de 1840 com o uso do daguerreótipo, um equipamento que não era capaz de produzir mais de uma cópia. A expansão da fotografia ocorreu primeiramente nas cidades de Recife, Salvador e Rio de Janeiro, quando esta ainda era a sede da Corte imperial. Nessas cidades, o intenso movimento dos portos facilitava o acesso em primeira mão às novidades tecnológicas provenientes da Europa. Mesmo distante da Corte e de outras cidades importantes do país, recém-elevada capital de Província, ao ocupar o lugar

\footnotetext{
${ }^{1} \mathrm{O}$ presente artigo é resultado parcial da minha pesquisa de Pós-Doutorado, realizado no Programa de Pós-Graduação em Sociologia da Universidade Federal do Paraná (UFPR), entre maio de 2014 e maio de 2015, sob a supervisão da Profa. Dra. Ana Luisa Fayet Sallas. Este trabalho também foi apresentado no III Seminário Fluminense de Sociologia GT: Arte e sociedade: pesquisas recentes, ocorrido entre 4 e 6 de novembro de 2014, na Universidade Federal Fluminense (UFF), em Niterói-RJ.

${ }^{2}$ Graduado em Ciências Sociais, Mestre, Doutor e Pós-Doutor em Sociologia pela Universidade Federal do Paraná. Docente das disciplinas de Sociologia e de Filosofia, na Secretaria de Estado da Educação do Paraná (SEED-PR). Endereço eletrônico: <lasalturi@yahoo.com.br>.
} 
da cidade portuária de Paranaguá, Curitiba se urbanizava e se adequava política e economicamente a sua nova condição, recebendo a visita de fotógrafos itinerantes.

Um dos primeiros desses profissionais a instalar seu estúdio fotográfico na cidade, no início da década de 1880, foi o alemão Adolpho Volk, cujo estabelecimento comercial funcionou em vários endereços. Atento às inovações da tecnologia, introduziu técnicas e equipamentos que ajudaram a abrir caminho àqueles que viessem a se aventurar nessa profissão. Nas primeiras décadas do século XX crescia o número de fotógrafos que se estabeleciam em Curitiba. Os jornais e revistas ilustradas da época fazem menção a vários profissionais e reproduzem suas fotografias. Dentre eles, o Boletim Casa Romário Martins destaca Bernardo Heisler, os irmãos Joseph e Augusto Weiss, Max Kopf, Lehmann \& Barthes, Octávio Lustoza \& Cia, Franklin Soares, José Gonçalvez Vasquez, Arthur Wischral, Frederico Lange, João Baptista Groff, Alberto Oncken e Armin Henkel (BOLETIM CASA ROMÁRIO MARTINS, 2005).

Os registros fotográficos deixados no Brasil pelos alemães foram importantes para a construção da iconografia nacional. Em seu livro Fotógrafos alemães no Brasil do século XIX (VASQUEZ, 2000), o fotógrafo Pedro Karp Vasquez comenta que os países germânicos tiveram um importante papel no desenvolvimento e aperfeiçoamento de diversas descobertas relacionadas à fotografia. As inovações técnicas introduzidas pelos alemães e austríacos não se limitaram às invenções de equipamentos, mas também aos procedimentos, como o retoque dos negativos com intenções corretivas e criativas. Além disso, a Alemanha se destacou na sistematização do ensino da fotografia ao tratá-lo de forma profissional, profunda e consequente, diferentemente da tendência generalizada em outros países, cujo ensino se dava com o contato direto com o fotógrafo.

No que se refere à fotografia de paisagem produzida desde o século XIX, esta consistia numa tarefa árdua e de retorno muitas vezes não assegurado, de modo que os profissionais que se dedicavam ao gênero não o faziam exclusivamente. A comercialização da fotografia de paisagem tinha uma clientela bem restrita, ficando circunscrita aos principais centros urbanos da época. A maioria dos fotógrafos dessa época se dedicou mais ao retrato para garantir subsistência. Além disso, a produção fotográfica paisagística brasileira sofreu forte influência da tradição pictórica acadêmica. Isto porque os fotógrafos tentavam explorar um filão comercial já instituído ou porque muitos deles eram também pintores, desenhistas ou gravadores. Os imigrantes de origem europeia tornaram-se um novo público consumidor desse gênero fotográfico, isto porque desejavam mostrar a paisagem local aos parentes que haviam permanecido na Europa ou ainda porque já estavam habituados com o uso da iconografia na decoração de suas residências. 
Arno Arthur Alvin Armin Henkel nasceu na Alemanha, em 1882. Veio para o Brasil no início do século XX, como desenhista e linotipista. Aprendeu a fotografar a partir de livros e especializou-se em cartões postais e em fotografia industrial. Além de fotógrafo, foi pintor e cinegrafista amador. Esteve vinculado a algumas instituições locais, tendo trabalhado para a Companhia Força e Luz, para o Departamento de Água e Esgoto e para a Rede Ferroviária Federal. A Photo Henkel, seu primeiro estúdio, funcionava na Travessa Alfredo Bufren, n. 46, na região central de Curitiba, próximo ao prédio histórico da Universidade Federal do Paraná e à Praça Santo Andrade. Em 1948, Henkel se mudou para a Avenida Sete de Setembro, n. 1594, também na região central da cidade, onde trabalhou até 1962, ano em que faleceu. Após sua morte, sua esposa deu continuidade às atividades no estúdio fotográfico (CASA ROMÁRIO MARTINS, 1982).

As fotografias de Armin Henkel selecionadas para análise foram produzidas a partir de várias excursões pelo Estado do Paraná realizadas pelo fotógrafo entre o final da década de 1930 e início da década de 1950. A temática abrange geograficamente as regiões do Litoral do Paraná, do Iguaçu e dos Campos Gerais. Ao analisá-las, há se de fazer alusão ao ensaio A filosofia da paisagem, do filósofo e sociólogo alemão Georg Simmel, que afirma que é preciso que certo conteúdo do campo de visão cative o espírito humano para que este possa ver os elementos da natureza como paisagem. A natureza é uma totalidade e a paisagem é um conjunto de elementos presididos pelo conceito unificador que confere sentido aos construtos do olhar, que recai sobre a natureza e que isola desta um pedaço. Trata-se de um processo exclusivamente humano, despertado por um "sentimento da natureza" que só se desenvolveu na época moderna (SIMMEL, 1996).

\section{AS EXCURSÕES}

Armin Henkel era casado com Anna Lange, irmã do pintor e cientista Frederico Lange de Morretes, cuja família era descendente de alemães ${ }^{3}$. Armin ensinou fotografia à esposa e juntos fizeram muitas excursões pelo Estado do Paraná em busca da observação, de registros e de contato com a natureza. É preciso destacar que esse tipo de excursão é uma prática típica da cultura dos povos germânicos. Em certa medida, a herança cultural proveniente da origem alemã do casal pode

\footnotetext{
${ }^{3}$ Sobre a trajetória social e a produção de Frederico Lange de Morretes, ver SALTURI, 2007.
} 
explicar a afeição de ambos pela prática do montanhismo e pela paisagem paranaense, cujos elementos característicos foram registrados em suas fotografias. Essa ligação com a natureza pode ser vista de uma forma semelhante na produção iconográfica dos pintores paranaenses de descendência alemã como Frederico Lange de Morretes, Kurt Boiger e Arthur Nísio ${ }^{4}$.

$\mathrm{Na}$ fotografia abaixo (figura 1), Armin segura uma máquina fotográfica ao lado de sua esposa, se preparando para uma seção fotográfica no Pico da Farinha, na Serra do Mar. A fotografia, que possui um carimbo do seu estúdio fotográfico na parte de trás. É possível perceber o entusiasmo dos Henkel frente à paisagem e ao seu possível registro.

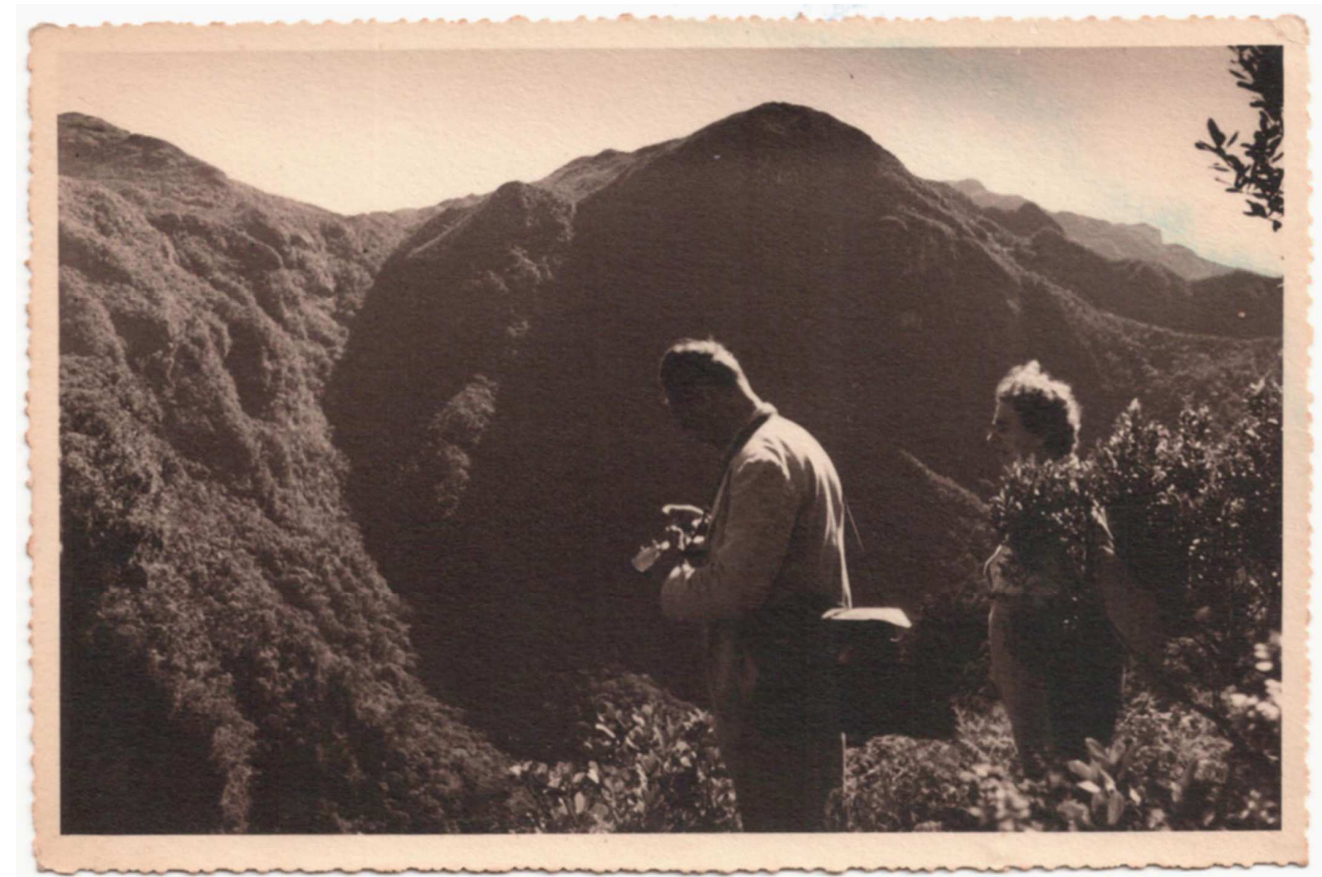

FIGURA 1 - HENKEL, Armin. [Photo]. Pico da Farinha, Serra do Mar. 1938. 11,5 x 17 cm.

$\mathrm{Na}$ fotografia seguinte aparecem dois dos excursionistas que acompanhavam o casal. Numa entrevista publicada em 1984, o artista-gravador portenho José Peon (1889-1972) fornece informações sobre a excursão, quando fixaram uma placa de bronze alusiva ao feito:

Custou-nos muito escalar o pico por nós batizado de Abrolhos. Tivemos que abrir picadas, marcar rotas, tatear, recuar e avançar. A meio caminho há uma lombada que se tornou ponto obrigatório de almoço. Como sempre sucede, o trecho final é o mais difícil. Era pequeno, mas nos reclamou uma hora e meia de marcha. Minha palavra é incapaz de descrever a nossa emoção quando, a 4 de setembro, finalmente chegamos ao topo. Éramos

\footnotetext{
4 Sobre a produção pictórica com temática da paisagem do Paraná, consultar PINTORES DA PAISAGEM PARANAENSE, 2001.
} 
quatro: o casal Armin e Anna Henkel, denodada parelha de antigos marumbinistas, para quem a Serra do Mar não tem segredos e Alfonso Hatschbach, também um excursionista valente. Ficamos dominados. Para o lado do mar e do vale o panorama é soberbo. E superior ao que se alcança do próprio Marumbi (PEON, 1984, p. 5).

Ao lado de outros apreciadores na natureza, como José Peon, os Henkel eram integrantes de um clube denominado Bandeira Paranaense de Turismo (1933) do Movimento Marumbinista (1942), que fazia excursões em diversos lugares do Estado do Paraná. Em outra fotografia (figura 2), as letras impressas abaixo registram o local onde a mesma foi produzida: A Esfinge do Salto do Inferno, Rio Ipiranga. Nota-se a imagem da esfinge formada pelas rochas no lado esquerdo das três pessoas que estão em primeiro plano. No centro inferior da fotografia está um logotipo formado pelas iniciais ESAH estilizadas, referente ao estúdio fotográfico pertencente ao casal.

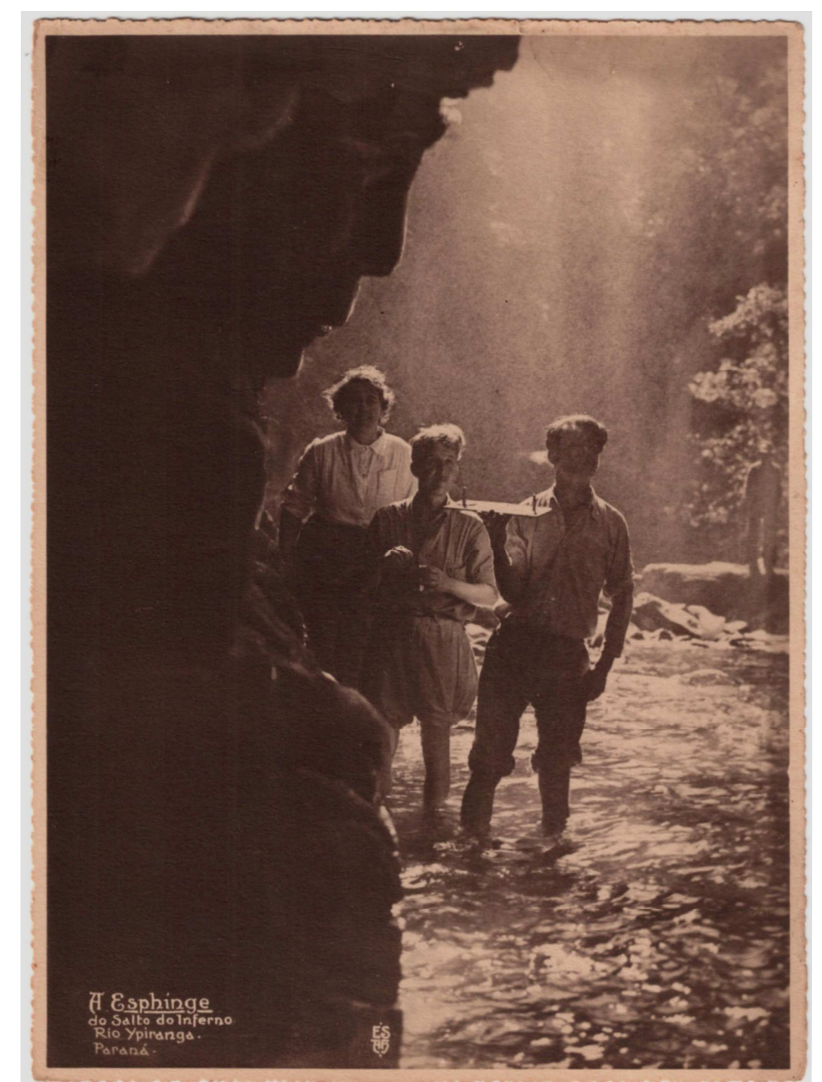

FIGURA 2 - HENKEL, Armin. A Esfinge do Salto do Inferno, Rio Ipiranga. 1938. 16 x $23 \mathrm{~cm}$.

A vegetação, o céu e o horizonte aparecem em outra fotografia que registra a passagem do grupo de excursionistas pela serra, em meio às montanhas que formam o conjunto do Marumbi. 
Nela, a serra é vista do Viaduto Engenheiro Cavalcanti (figura 3), na qual aparece a Estrada da Graciosa:

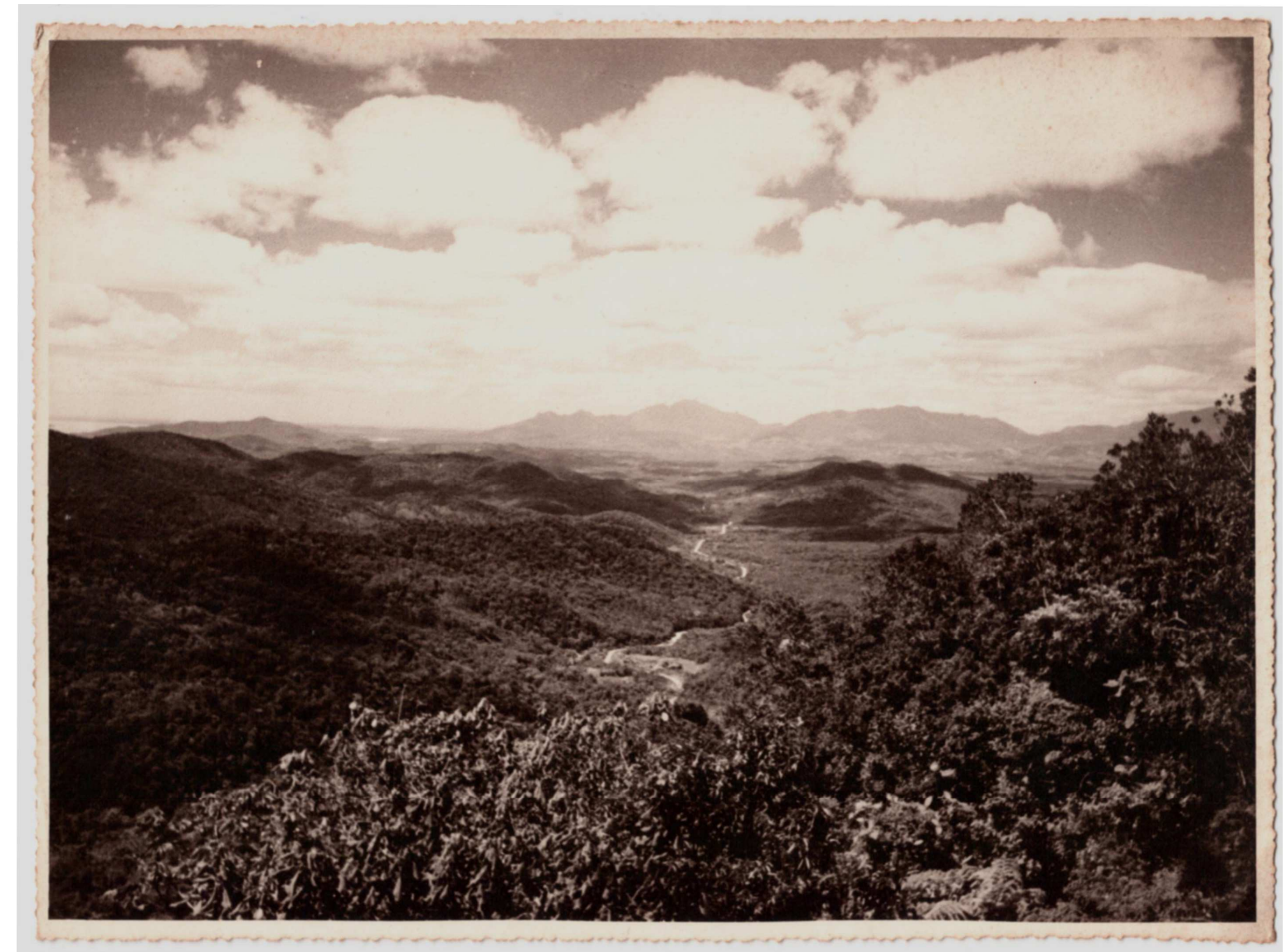

FIGURA 3 - HENKEL, Armin. Serra da Graciosa visto do Viaduto Cavalcanti. 1937. 16 x $23 \mathrm{~cm}$.

Outro tema fotografado por Armin é a Estrada de Ferro que liga a cidade litorânea de Paranaguá à capital Curitiba. Um dos principais responsáveis por sua construção foi o engenheiro alemão Rudolph Lange, pai de Anna, cuja infância foi marcada pelo contato com a natureza da região. Considerada uma obra-prima da engenharia, essa estrada de ferro representa o domínio do homem sobre a natureza, justamente porque para que a construção de sua linha férrea se concretizasse, foi necessário ultrapassar vários obstáculos do relevo.

A Estrada de Ferro Paranaguá-Curitiba foi inaugurada em 2 de fevereiro de 1885 e é a primeira ferrovia do Estado do Paraná, foi construída principalmente devido às necessidades do comércio entre as regiões. Possui 14 túneis escavados na rocha, 41 pontes e viadutos em dimensões colossais, utilizando estrutura metálica, que passam pelo meio da Mata Atlântica. O Viaduto 
Carvalho, que aparece na fotografia a seguir (figura 4), foi construído com grande tenacidade e está a mais de 900 metros de altura, usando como suporte muros de até 100 metros de altura.

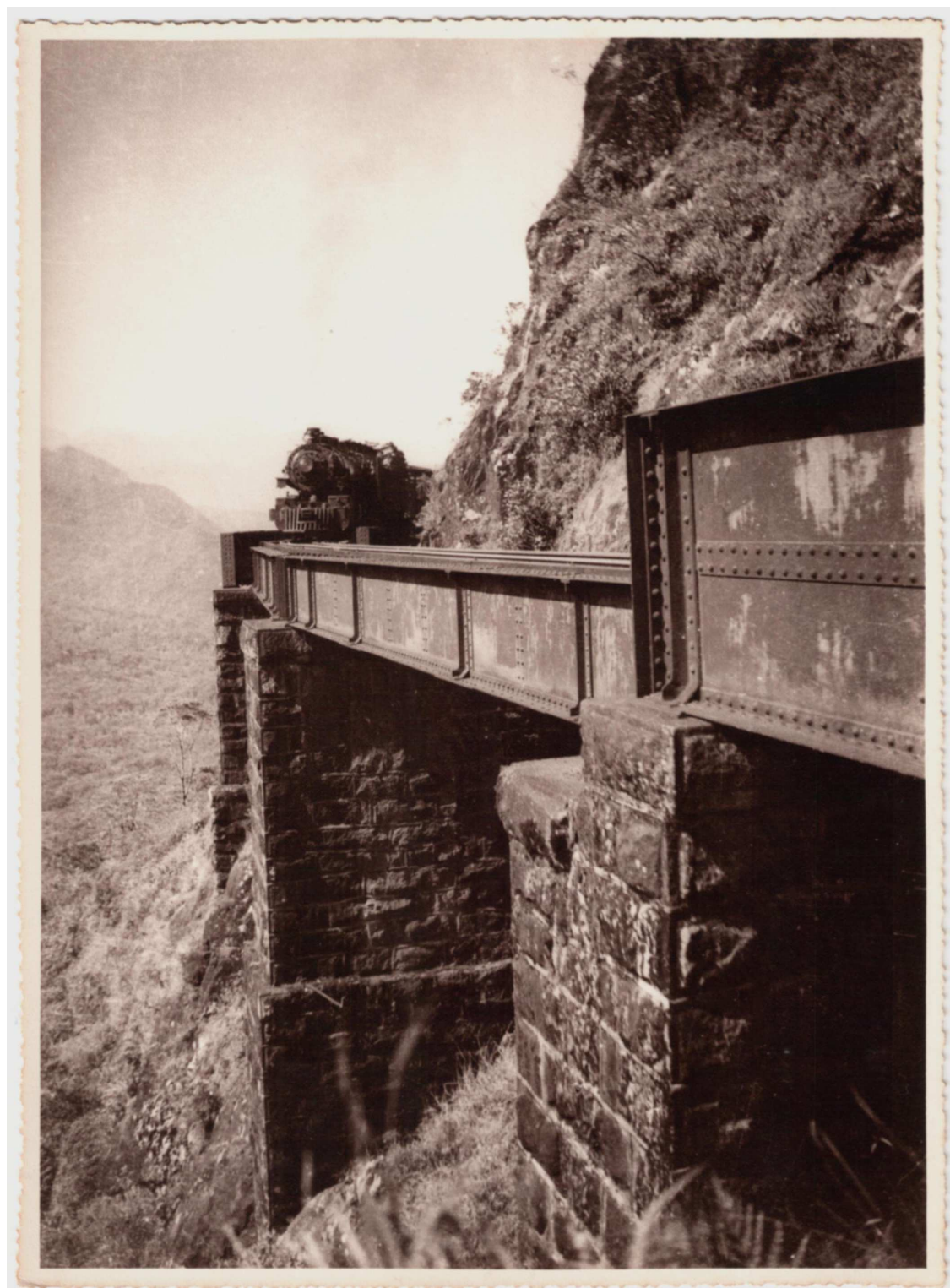

FIGURA 4 - HENKEL, Armin. Viaduto Carvalho, Estrada de Ferro Paranaguá-Curitiba. [19--]. 16 x 23 cm.

Ao analisar a produção fotográfica de Armin Henkel com a temática do litoral paranaense, com destaque para as cidades de Morretes (figuras 5), percebe-se uma forte referência à pintura, não só pelos temas escolhidos, mas também em relação ao enquadramento. Isto porque conforme afirma o historiador da arte francês Pierre Francastel, a fotografia revelou não só o caráter real da visão tradicional de como se dava o registro das imagens, mas seu caráter sistemático, ao serem produzidas tendo como referência a visão artística clássica (FRANCASTEL, 1990). A fotografia 
herdou da pintura o processo de criação da imagem sobre um espaço bidimensional e um suporte retangular.

No que se refere aos temas, é interessante lembrar a afirmação do historiador da arte inglês Kenneth Clark, de que o ser humano está rodeado por árvores, flores, rios, colinas e nuvens, elementos que inspiram curiosidade e respeito, despertando prazer. Isto porque tais elementos são componentes de uma ideia a que chamamos natureza (CLARK, 1961). Em relação ao enquadramento, há um esquema de construção da imagem, o qual Ernst Gombrich define como schemata, no qual a apreensão do que é visto é conformado numa determinada tradição do olhar, que serve como ponto de partida para criá-las (GOMBRICH, 2007).

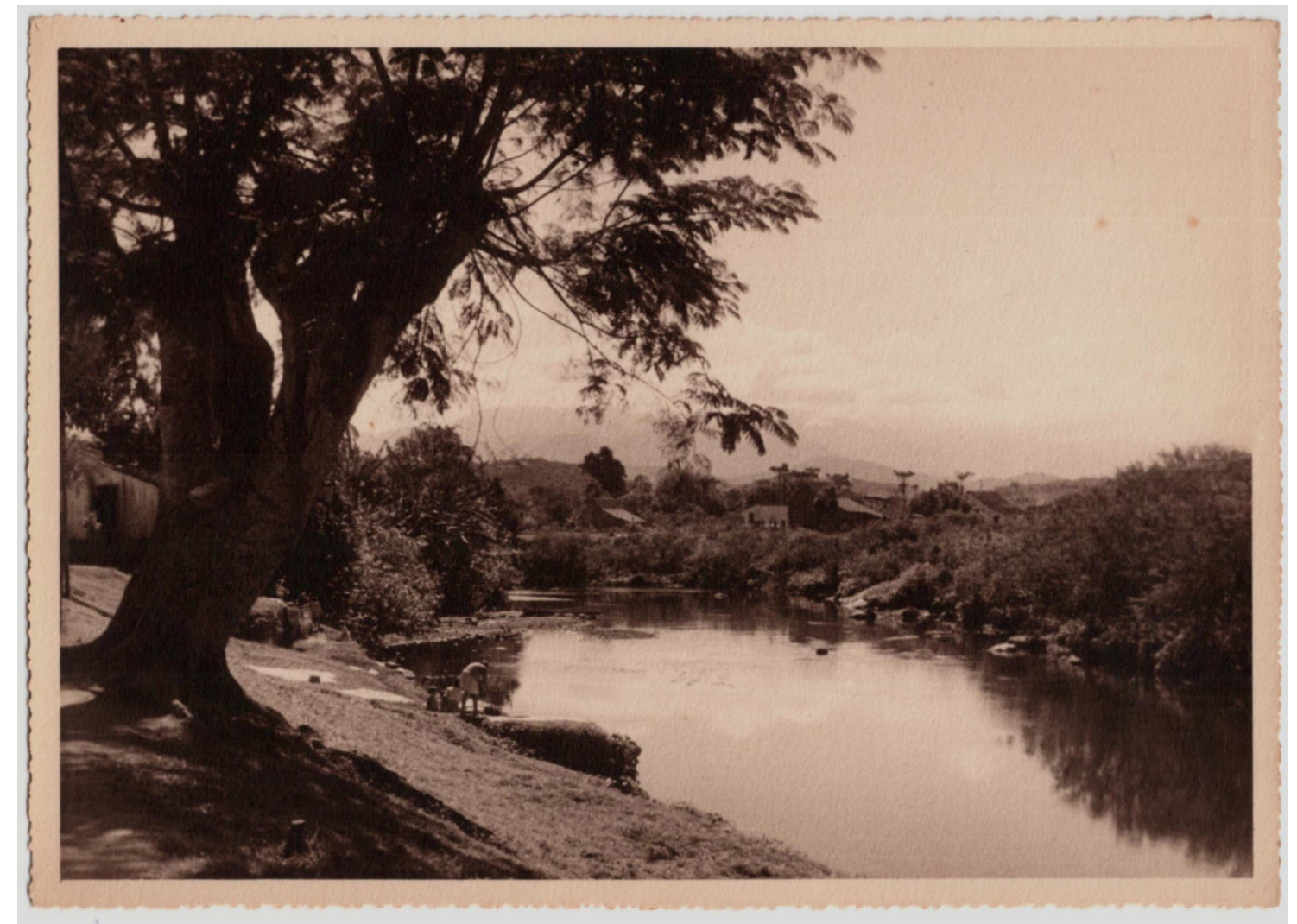

FIGURA 5 - HENKEL, Armin. Morretes. [19--]. 16 x 23 cm.

Na produção de Armin Henkel novamente aparecem fotografias que envolvem a temática das águas, mas em outra região do Estado do Paraná, bem distante do litoral. É interessante nessas imagens o estado contemplativo, lúdico e de mistério proporcionado pela temática que envolve paisagens aquáticas. Os rios e o mar são elementos estimulantes da imaginação, sendo determinantes também na valoração da paisagem. 
A cidade de Foz do Iguaçu está localizada no extremo oeste do Estado, na fronteira com a Argentina e com o Paraguai. Criado em 1914, o município viria a se tornar o segundo principal destino para turistas estrangeiros no país e o primeiro da região sul. A cidade é conhecida pelas Cataratas do Iguaçu (figura 6), que são formadas pelas quedas d'água do rio Iguaçu. Nas fotografias em que retratou as Cataratas do Iguaçu, Armin evidencia a extensão formada pelas quedas d'água. Sua escolha pelo enquadramento ainda serve como ponto de referência para os atuais anúncios publicitários dessa região turística.

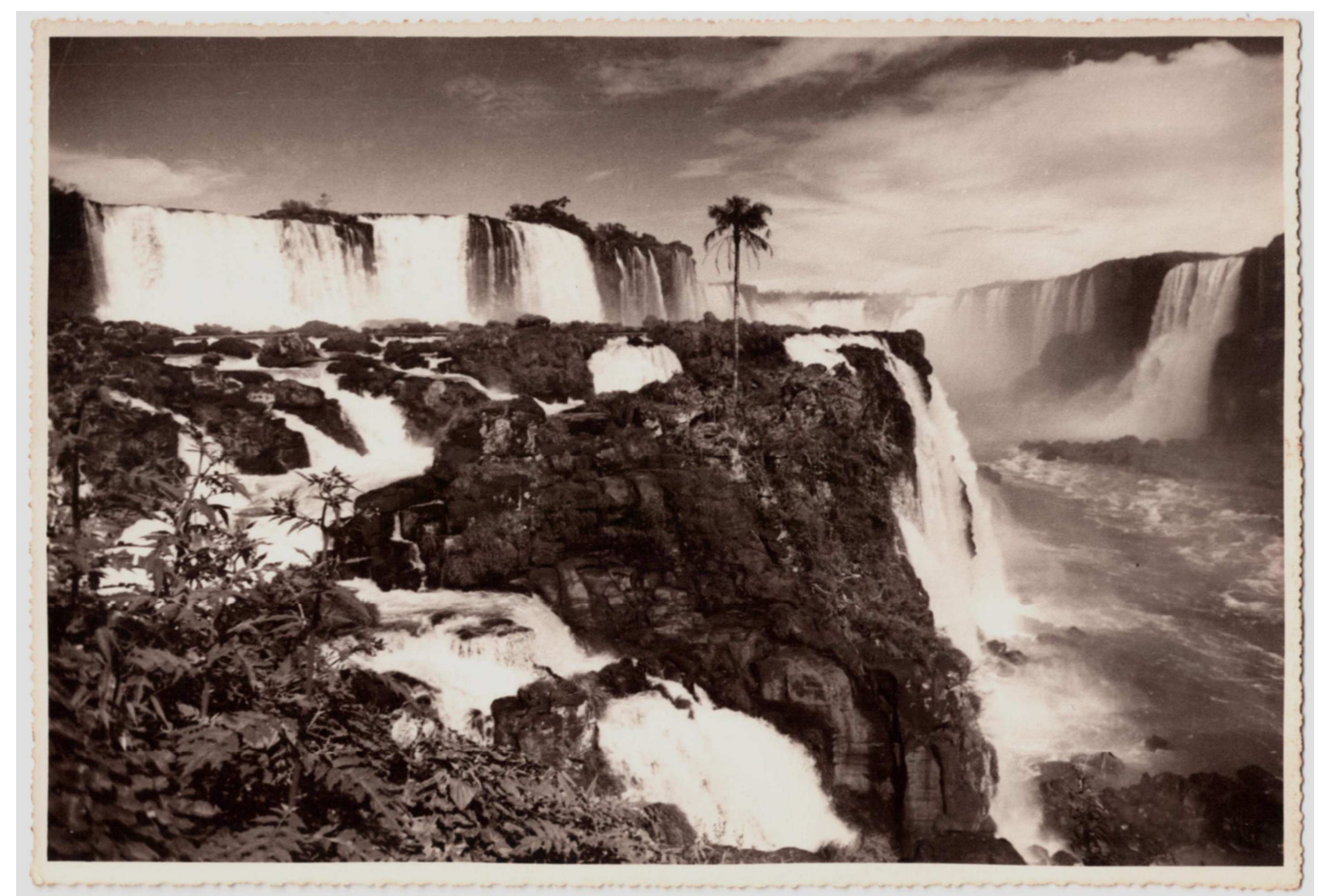

FIGURA 6 - HENKEL, Armin. Saltos do Rio Iguaçu, Paraná. [19--]. 16 x 23 cm.

No contato com as fotografias de Armin Henkel se percebe como as mesmas são muito mais que registros de eventos ocasionais. Nesse ponto, vale lembrar um apontamento do historiador britânico Simon Schama argumenta que a paisagem é resultado da cultura antes de ser natureza; um constructo da imaginação humana projetado sobre mata, água e rocha (SCHAMA, 1996). Inserida no contexto desta última projeção da imaginação, a fotografia a seguir (figura 7) tem como tema o conjunto de formações rochosas que deram origem ao Parque Estadual de Vila Velha, situado na cidade de Ponta Grossa, região dos Campos Gerais. Conhecido também como um dos principais pontos turísticos do Estado, o local atrai visitantes por suas famosas formações rochosas que 
sugerem imagens de animais, objetos e figuras humanas, constituindo-se em mais uma das marcas identitárias do Estado do Paraná.

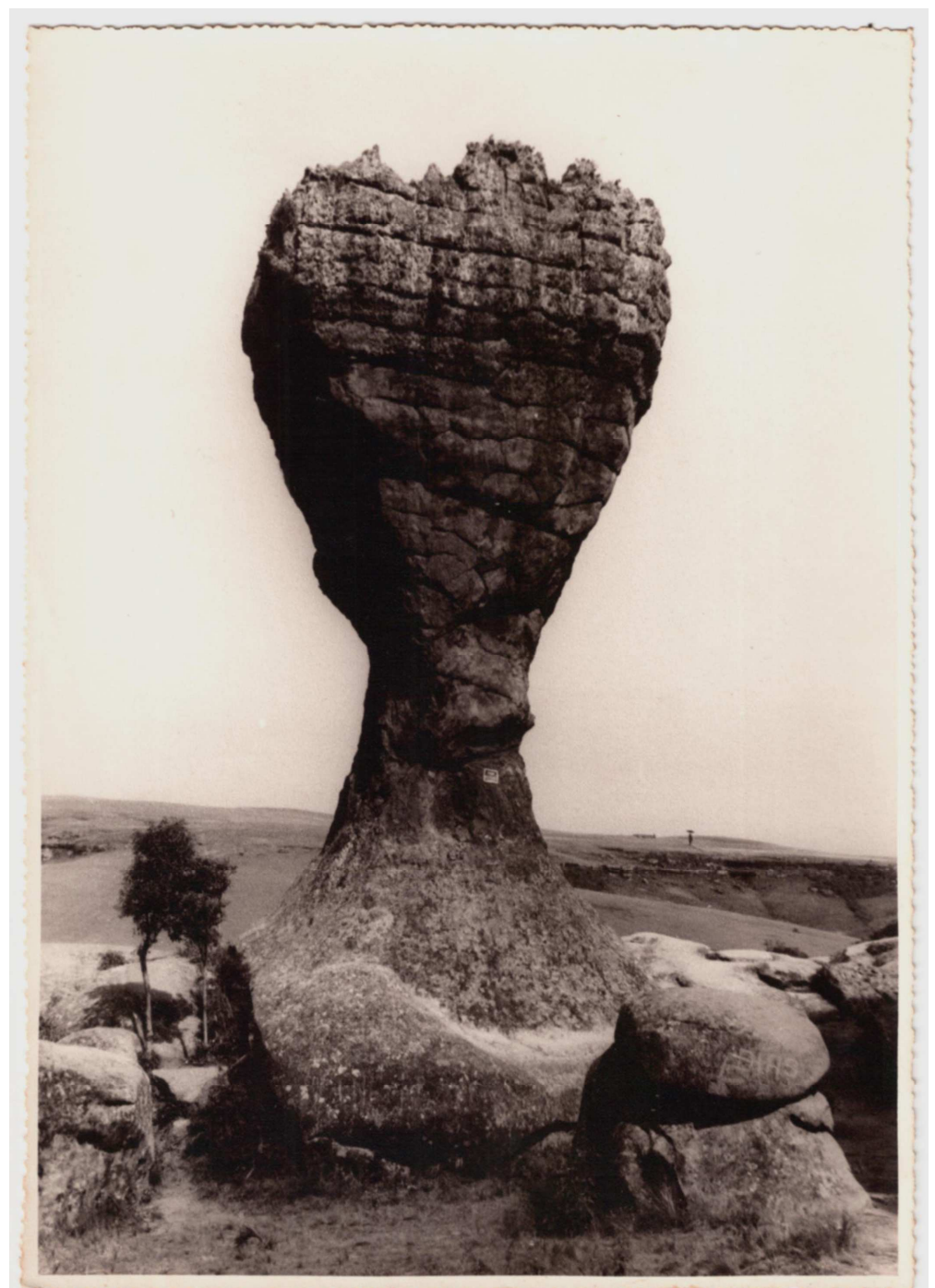

FIGURA 7 - HENKEL, Armin. Vila Velha, Paraná, Taça. [19--]. 16 x 23 cm.

Outra referência pictórica marcante na produção fotográfica de Armin são os pinheiros. Essa temática está fortemente relacionada com o paranismo, sentimento de enaltecimento pelo Estado do Paraná que se manifestou nas esferas política e cultural nas primeiras décadas do século XX. Nas artes visuais, essa afeição pelo Paraná foi colocada em prática em meados da década de 1920, quando atingiu o caráter de um movimento integrado. Em produções artísticas, literárias e históricas, os representantes do Movimento Paranista se preocupavam com a questão de promover uma identidade local utilizando como temática a flora, a fauna e o indígena. Vários pintores 
paranaenses da época retratavam esses elementos em suas telas. Dentre eles, se destacam Alfredo Andersen, Theodoro De Bona, Arthur Nísio e Frederico Lange de Morretes (SALTURI, 2009).

A pinha, os pinhões e os sapés são respectivamente os frutos, as sementes e os ramos do pinheiro, árvore considerada símbolo do Estado do Paraná. Na fotografia a seguir (figura 8), ao retratar um conjunto de pinhas, pinhões e sapés, Armin utiliza como suporte referencial a naturezamorta, gênero da pintura no qual se representam frutas, flores, objetos e/ou animais abatidos. O resultado final é o registro fotográfico transformado num cartão postal.

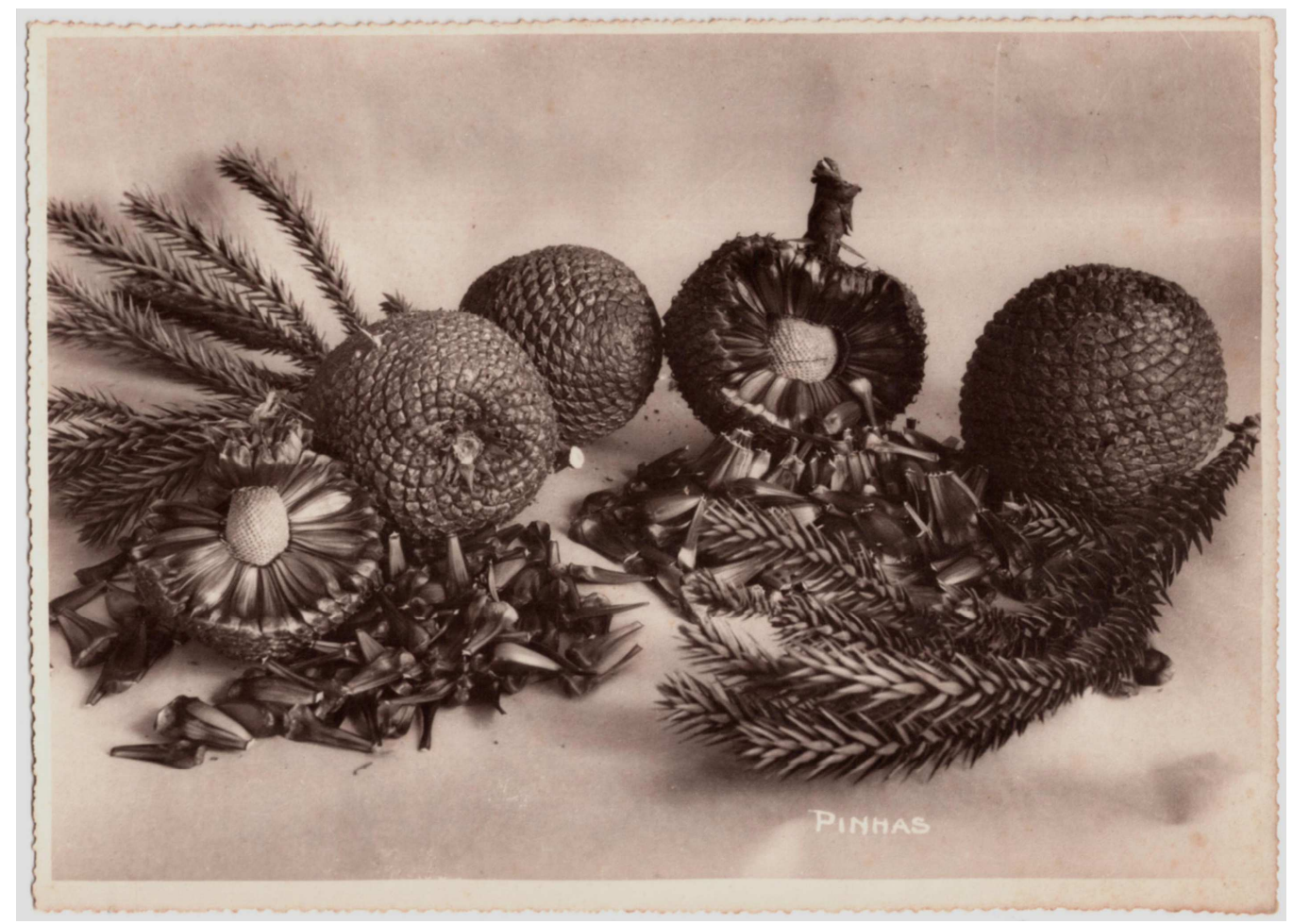

FIGURA 8 - HENKEL, Armin. Pinhas. [19--]. 16 x 23 cm.

Ao lado dos pinheiros, a erva-mate e os imigrantes compõem o cenário cultural da região. Entre a primeira metade do século XIX e as primeiras décadas do século XX a erva-mate foi uma das principais atividades econômicas do Estado do Paraná. A erva-mate é uma árvore originária da região subtropical da América do Sul, presente no sul e centro oeste do Brasil, norte da Argentina, Paraguai e Uruguai. Os ervais eram encontrados em quase todo o território paranaense, principalmente nas regiões onde havia muitos pinheiros. Alguns povos indígenas tinham o hábito de beber infusões com suas folhas. Esse hábito continua popular nessas regiões, além do consumo como chá quente ou gelado. 


\section{CONSIDERAÇÕES FINAIS}

Ao condensar realidades sociais e captar aspectos que um documento escrito não revela, a fotografia se torna um precioso documento para realização de estudos sobre determinada época. A partir da produção fotográfica de Armin Henkel, pode-se concluir que sua obra possui grande importância sociológica e histórica. Isto porque, em âmbito local, suas fotografias remetem a um contexto cultural e político no qual a representação da natureza está articulada com questões de afirmação identitária do Estado do Paraná. Num sentido mais amplo, suas fotografias revelam vários aspectos da relação entre o ser humano e a natureza.

Não há paisagem sem um observador. As fotografias de Armin Henkel condensam uma visão muito particular sobre a região sul do Brasil, na qual as paisagens pretendem identificar o Paraná. Porém, no que se refere a essa identificação, esses registros não carregam um sentido objetivo e explícito, na medida em que não foram produzidos tendo essa finalidade prática. Considerando a necessidade de uma identidade própria, vigente nas artes visuais do período, essas fotografias expressam essas ideias de uma forma subjetiva.

Essa produção fotográfica permite compreender como se constituiu um imaginário acerca da paisagem paranaense, que viria a influenciar outros olhares, em outras épocas. Deste modo, o conhecimento sobre a obra de Armin Henkel é fundamental, na medida em que permite compreender como a mesma auxiliou na construção de uma iconografia para a região. O que é mais do que suficiente para justificar o resgate desse personagem que caiu no esquecimento.

\section{REFERÊNCIAS BIBLIOGRAFICAS}

BOLETIM CASA ROMÁRIO MARTINS. Fotos de estúdio: imagens construídas. Curitiba: Fundação Cultural de Curitiba, v. 29, n. 127, jul., 2005.

CASA ROMÁRIO MARTINS. Mostra de fotografias do Paraná de Ontem. Curitiba: Sala Funarte, Fundação Cultural de Curitiba, 1982.

CLARK, Kenneth. Paisagem na arte. Lisboa: Ulisseia, 1961. 
FRANCASTEL, Pierre. Pintura e sociedade. São Paulo: Martins Fontes, 1990.

GOMBRICH, Ernst Hans. Arte e ilusão: um estudo da psicologia da representação pictórica. 4 ed. São Paulo, Martins Fontes, 2007.

PEON, José. Da montanha: Abrolhos, 4 de setembro de 1937. Gazeta do Povo, $1^{\circ}$. de setembro de 1984. Caderno Gazetinha. p. 5.

PINTORES DA PAISAGEM PARANAENSE. Curitiba: Secretaria de Estado da Cultura: Solar do Rosário, 2001.

SALTURI, Luis Afonso. Frederico Lange de Morretes, liberdade dentro de limites: trajetória do artista-cientista. Curitiba, 2007. 255 f. Dissertação (Mestrado em Sociologia). Setor de Ciências Humanas, Letras e Artes, Universidade Federal do Paraná.

SALTURI, Luis Afonso. Paranismo, movimento artístico do sul do Brasil no início do século XX. Perifèria: revista de recerca i formació en Antropologia. Espanha, v. 11, p. 1-22, 2009. Disponível em:〈http://antropologia.uab.es/Periferia/Articles/6-salturi.pdf $>$.

SHAMA, Simon. Paisagem e memória. São Paulo: Companhia das Letras, 1996.

SIMMEL, Georg. Filosofia da paisagem. Revista Política e trabalho. João Pessoa, n. 12, p. 15-24, set. 1996.

VASQUEZ, Pedro Karp. Fotógrafos alemães no Brasil do século XIX. São Paulo: Metalivros, 2000.

\begin{abstract}
This article discusses the work of German photographer Armin Henkel (1882-1962) who settled in Curitiba. The photographs are various Paraná's locations, produced between the end 1930s and mid-1950s. This material is analyzed from the Sociology's theoretical and methodological assumptions. This is the first work of this photographer who owned a photography studio in Curitiba and whose biographical information is scarce. Armin Henkel's work has great sociological and historical importance, to the extent that their photographs registers moments of the Brazilian culture and landscape, productions that later turned into postcards.
\end{abstract}

Keywords: Armin Henkel. Paraná photography, Paraná landscape. 